\title{
EFEK INTERVENSI TRAINING DAN COACHING KEBERMAKNAAN KERJA TERHADAP KINERJA KARYAWAN
}

\author{
THE EFFECT OF MEANINGFUL WORK TRAINING AND COACHING INTERVENTION \\ ON EMPLOYEE PERFORMANCE
}

\author{
Eduardo Edwin Ang*), Diah Dharmayanti*), dan Deborah C. Widjaja*) \\ *) Fakultas Bisnis dan Ekonomi, Universitas Kristen Petra \\ Jl. Siwalankerto 121-131, Surabaya 60236, Indonesia
}

\begin{abstract}
This study aims to determine the extent of meaningful work interventions in the form of training and coaching can improve room attendant's performance (housekeeping department) at Bumi Surabaya City Resort. The research was conducted by the action research method with three stages namely Pre ODI (Diagnosis), ODI (Design and Implementation), and Post ODI (Expected Outcome). ODI itself stands for Organization Development Intervention, which means a structured program designed to solve problems, thereby enabling organizations to achieve goals. Based on Pre ODI results, room attendants have low performance because room attendants do not yet understand the purpose and meaning of their work. Therefore at the ODI stage, researchers provide meaningful work interventions with tools in the form of training and coaching to improve employee performance. To see an improvement in employee performance, the Post ODI researchers conducted a different test (Paired Sample T-Test) before and after the intervention. The results showed that meaningful work training and coaching intervention were able to increase employee performance scores from 3,03 (Pre ODI) to 3,43 (Post ODI). Thus, the research hypothesis can be accepted that there are differences in the average employee performance scores before and after the intervention.
\end{abstract}

Keywords: coaching, employee performance, meaningful work, organization development intervention, training

\begin{abstract}
Abstrak: Penelitian ini bertujuan untuk mengetahui sejauh mana intervensi kebermaknaan kerja dalam bentuk training dan coaching mampu meningkatkan kinerja room attendant (housekeeping department) Bumi Surabaya City Resort. Penelitian dilakukan dengan metode action research dengan tiga tahapan, yaitu Pre ODI (Diagnosa), ODI (Desain dan Implementasi), dan Post ODI (Expected Outcome). ODI sendiri merupakan singkatan dari Organization Development Intervention yang berarti program terstruktur yang dirancang untuk memecahkan masalah, sehingga memungkinkan organisasi untuk mencapai tujuan. Berdasarkan hasil Pre ODI, room attendant memiliki kinerja yang rendah karena room attendant belum memahami tujuan dan makna bekerjanya. Oleh karena itu, pada tahap ODI, peneliti memberikan intervensi kebermaknaan kerja dengan tools berupa training dan coaching untuk meningkatkan kinerja karyawan. Untuk melihat peningkatan terhadap kinerja karyawan, maka pada tahap Post ODI peneliti melakukan uji beda (Paired Sample T-Test) sebelum dan sesudah dilakukannya intervensi. Hasil penelitian menunjukkan intervensi training dan coaching kebermaknaan kerja mampu meningkatkan score kinerja karyawan dari 3,03 (Pre ODI) menjadi 3,43 (Post ODI). Dengan demikian, hipotesis penelitian dapat diterima yaitu terdapat perbedaan rata-rata skor kinerja karyawan sebelum dan setelah dilakukannya intervensi.
\end{abstract}

Kata kunci: coaching, kebermaknaan kerja, kinerja karyawan, organization development intervention, training

\footnotetext{
${ }^{1}$ Alamat Korespondensi:

Email: edwinang678@gmail.com
} 


\section{PENDAHULUAN}

Industri perhotelan di Surabaya terus berkembang dan semakin kompetitif. Hal ini didukung dengan pernyataan Herry Siswanto (Ketua Perhimpunan Hotel dan Restoran Indonesia Jawa Timur, 2019) bahwa persaingan antara hotel baru dengan lama tidak terelakkan lagi. Pertumbuhan hotel yang terus terjadi memengaruhi tingkat okupansi. Persaingan juga tidak hanya terjadi pada hotel dengan kelas yang sama, melainkan juga pada kelas yang lebih tinggi atau lebih rendah. Dikutip dari kompas.com (2019), Senior Research Director Colliers International Indonesia Ferry Salanto menyebutkan akan ada 988 kamar baru di Surabaya dari hotel berkelas bintang tiga, empat dan lima tahun 2019. Ini menambah 14.139 kamar yang ada pada tahun 2018. Selanjutnya, pada 2020 ada tambahan 488 kamar dari hotel bintang 3 sebanyak 288 kamar dan bintang lima 200 kamar (Almutoif, 2019).

Melihat kondisi ini maka sebagai hotel berbintang lima dan telah berdiri lama, Bumi Surabaya City Resort perlu terus meningkatkan kualitasnya sehingga tidak terkalahkan dengan hotel baru yang bermunculan. Salah satu kualitas yang perlu terus diperhatikan adalah kualitas pelayanan karena industri perhotelan merupakan industri jasa yang sangat memperhatikan faktor pelayanan kepada konsumen. Sebuah hotel akan selalu diminati dan diingat oleh konsumen apabila kualitas pelayanan yang diberikannya tinggi. Dalam menunjang kualitas pelayanan, kinerja sumber daya manusia memiliki peranan penting dalam memberikan pelayanan itu sendiri. Pentingnya Sumber Daya Manusia (SDM) di sektor pariwisata adalah manusia (people) merupakan sumber daya yang sangat penting di sebagian besar organisasi. Khususnya di organisasi berbasis jasa (service-based organization), SDM berperan sebagai faktor kunci dalam mewujudkan keberhasilan kinerja (Evans et al. 2003).

Kinerja karyawan menjadi penting dalam menentukan kinerja keseluruhan perusahaan. Aguinis dan Kraiger (2009) mendefinisikan kinerja karyawan sebagai kemampuan individu untuk melakukan tugas pekerjaannya dengan memiliki keterampilan, pengalaman, sikap, dan motivasi yang dibutuhkan. Oleh karena itu, perusahaan selalu berusaha untuk terus meningkatkan kinerja sumber daya manusia yang dimilikinya untuk menunjang kinerja perusahaan secara keseluruhan.
Untuk memberikan kinerja terbaik, karyawan perlu memiliki mindset bahwa pekerjaan yang dilakukannya bermakna sehingga kegiatan yang dilakukan seharihari tidak hanya sekedar untuk memenuhi kewajiban bekerjanya akan tetapi mampu secara mendalam dipahami bahwa pekerjaan yang dilakukannya memiliki makna yang lebih luas. Riset pun menunjukkan bahwa bekerja demi kebermaknaan ini akan menimbulkan perasaan positif dan pencapaian sasaran jangka panjang yang lebih baik (Rachman dan Jakob, 2018).

Salah satu kekuatan pendorong dalam proses ini adalah pencarian makna dalam pekerjaan. Pekerjaan yang bermakna mengharuskan karyawan untuk memahami pentingnya apa yang mereka lakukan (Wrzesniewski et al. 2003). Steger et al. (2012) mengungkapkan bahwa perasaan bermakna di dalam pekerjaan ialah membuat makna kerja itu sendiri sehingga dapat memberikan kontribusi yang optimal bagi organisasi. Kebermaknaan kerja menjadi penting bagi karyawan karena karyawan yang menemukan makna dalam pekerjaanya cenderung lebih puas, engaged, dan pada gilirannya lebih produktif. Karyawan bekerja lebih keras, pintar, bersemangat, dan kreatif (Ulrich dan Ulrich, 2010). Penelitian terdahulu telah memberikan bukti empiris tentang hubungan antara kebermaknaan kerja dan kinerja karyawan. Kebermaknaan kerja dapat meningkatkan kesadaran karyawan tentang nilai pekerjaan mereka, yang pada gilirannya memotivasi mereka untuk berkinerja baik (Spreitzer,1995). Tong (2018) menunjukkan bahwa terdapat hubungan positif dan signifikan antara pekerjaan yang bermakna dan kinerja tugas, menunjukkan bahwa penyediaan tugas-tugas ideal yang dilakukan oleh perawat terutama dipengaruhi oleh persepsi mereka tentang kebermaknaan pekerjaan mereka. Lebih lanjut dalam penelitian Zeglat dan Janbeik (2019) ketika karyawan mendapatkan makna dalam apa yang mereka lakukan, maka mereka akan melakukan upaya untuk mencapai tingkat kinerja yang terbaik.

Penelitian ini dilakukan dengan melihat adanya permasalahan kinerja karyawan yang terjadi di Bumi Surabaya City Resort yaitu ditemukannya kinerja room attendant yang menurun beberapa bulan terakhir ini. Setelah dilakukan analisa yang mendalam maka ditemukan akar penyebab permasalahan kinerja karyawan yang menurun ini dikarenakan room attendant belum memahami makna bekerjanya. Peneliti pun memilih training dan coaching sebagai tools untuk menyampaikan teori kebermaknaan kerja 
guna meningkatkan kinerja room attendant. Komponen pelatihan (training) mempunyai pengaruh penting terhadap kinerja dan motivasi pegawai (Julianry et al. 2017). Coaching merupakan suatu proses untuk membantu karyawan dalam memperjelas tujuan karir, menghadapi potensi masalah dalam pekerjaan, dan meningkatkan kinerja karyawan (Cummings dan Worley, 2009).

Berdasarkan permasalahan dan penelitian terdahulu maka tujuan penelitian ini adalah mengetahui sejauh mana intervensi kebermaknaan kerja dalam bentuk training dan coaching mampu meningkatkan kinerja room attendant (housekeeping department) Bumi Surabaya City Resort.

\section{METODE PENELITIAN}

Lokasi penelitian dilakukan di Bumi Surabaya City Resort di daerah Jawa Timur. Kesediaan pihak hotel untuk menjadi objek penelitian merupakan alasan penentuan lokasi penelitian. Waktu penelitian dilakukan dalam kurun waktu tujuh bulan dimulai bulan Agustus 2019 hingga Februari 2020. Data acuan dalam penelitian ini adalah data primer dan data sekunder. Data primer didapatkan melalui observasi, wawancara, informal discussion, dan penilaian kinerja yang dibagikan kepada team leader untuk menilai kinerja room attendant serta self assessment guna room attendant menilai kinerja nya sendiri. Data sekunder yang digunakan merupakan data yang tersedia yang berguna untuk mendukung penelitian yang berasal dari pihak hotel dan pihak lain serta studi literatur dan penelitian terdahulu. Penelitian ini menggunakan teknik pengambilan sampel yaitu total sampling dimana jumlah sampel sama dengan populasi. Maka yang menjadi sampel dalam penelitian ini adalah seluruh room attendant yang berjumlah 39 orang.

Hipotesis penelitian ini adalah adanya perbedaan rata-rata skor kinerja karyawan sebelum dan setelah dilakukannya intervensi. Gambar 1 menjelaskan kerangka penelitian (Action Research) yang diawali dengan tahap Pre ODI dimana hasil diagnosa ditemukan kinerja room attendant mengalami penurunan beberapa bulan terakhir ini dikarenakan room attendant belum memahami makna dari pekerjaannya. Langkah selanjutnya tahap ODI dimana peneliti merancang dan mengimplementasikan intervensi kebermaknaan kerja dengan tools yang dipakai yaitu training dan coaching. Serta langkah yang terakhir yaitu Post ODI dimana peneliti mengevaluasi hasil kinerja room attendant apakah sudah mengalami peningkatan setelah dilakukannya intervensi.

Teknik analisis data yang digunakan adalah Paired Sample T-Test. Alasan penggunaan teknik analisis data ini karena peneliti ingin membandingkan skor kinerja room attendant sebelum dan sesudah dilakukannya intervensi. Rumus t-test (Siregar, 2015) yang digunakan untuk sampel berpasangan (paired) adalah sebagai berikut:

$$
t=\frac{\overline{x 1}-\overline{x 2}}{\sqrt{\frac{s 1^{2}}{n 1}}+\frac{s 2^{2}}{n 2}-2 r\left(\frac{s 1}{\sqrt{n 1}}\right)\left(\frac{s 2}{\sqrt{n 2}}\right)}
$$

Keterangan: $\chi 1$ (Rata-rata sampel 1); $\chi 2$ (Ratarata sampel 2); S1 (Simpangan baku sampel 1); S2 (Simpangan baku sampel 2); S12(Varians Sampel 1); $\mathrm{S}^{2}{ }^{2}$ (Varians Sampel 2); r (Korelasi antara dua sampel).

\section{HASIL}

\section{Pre ODI}

Pada tahap ini peneliti melakukan diagnosa terkait masalah yang terjadi di dalam organisasi. Penentuan masalah menjadi sangat penting karena nantinya akan menentukan jenis intervensi yang akan peneliti lakukan kedepannya.

\section{Observasi}

Ditahap ini peneliti melakukan observasi langsung di Bumi Surabaya City Resort. Dari hasil observasi, peneliti menemukan bahwa room attendant cenderung tidak bersungguh-sungguh dalam bekerja dimana hal tersebut juga didukung dengan hasil Service Excelence Observation yang peneliti lakukan bersama dengan Talent and Learning Manager dimana melalui observasi tersebut ditemukan bahwa terdapat kekurangan pada kamar yang sudah siap untuk dijual (vacant ready). Untuk mendukung hasil temuan observasi, Peneliti juga melakukan indepth interview, informal discussion, dan juga penilaian kinerja. 


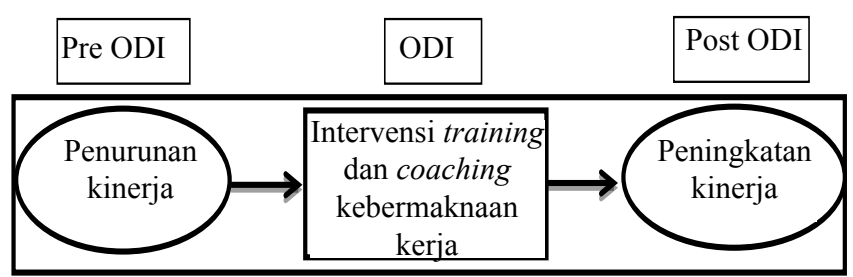

Gambar 1. Kerangka pemikiran penelitian

\section{Indepth Interview}

Untuk menunjang hasil observasi, peneliti juga melakukan wawancara mendalam. Wawancara ini membantu peneliti menggali informasi yang lebih dalam terkait permasalahan yang terjadi. Pertama peneliti melakukan wawancara dengan Talent \& Learning Manager. Hasil wawancara diperoleh informasi bahwa departemen yang menjadi concern management saat ini adalah housekeeping department terutama karyawan room attendant dikarenakan berdasarkan data observasi selama ini ditemukan kinerja room attendant menurun yang ditandai dengan kurangnya kesungguhan room attendant dalam melaksanakan pekerjaanya. Untuk memastikan hal tersebut, peneliti juga melakukan wawancara dengan Housekeeping Manager. Hasil wawancara didapatkan informasi yang sama bahwa memang kinerja room attendant beberapa bulan terakhir ini mengalami penurunan dan sewaktu ditanya mengenai tindakan apa yang diambil untuk memperbaiki kinerja room attendant, Housekeeping Manager menjawab bahwa melihat hal tersebut, team leader selaku atasan langsung dari room attendant kembali mengajarkan skill/ keterampilan bekerja kepada room attendant. Namun upaya tersebut ternyata tidak mampu untuk menunjang performance room attendant.

\section{Informal Discussion}

Untuk membantu pihak management maka peneliti melakukan informal discussion dengan team leader selaku atasan langsung dari room attendant serta room attendant sendiri sebagai objek penelitian untuk menggali lebih lanjut akar permasalahan ini. Pertama peneliti melakukan informal discussion dengan empat orang team leader dan dari hasil informal discussion didapati informasi bahwa kinerja room attendant selama ini mengalami penurunan dengan ciri-ciri room attendant terlihat tidak bersungguh-sungguh dalam menjalankan pekerjaan, room attendant cenderung pasif dan kurang berkoordinasi dengan sesama rekan kerja maupun divisi lain yang pada akhirnya mempengaruhi hasil kinerja mereka, room attendant kurang bersemangat saat menjalankan pekerjaannya, serta kurangnya inisiatif dari room attendant saat melihat hal-hal yang sebenarnya tidak sesuai dengan ketentuan perusahaan. Dari hasil informal discussion tersebut dapat peneliti simpulkan bahwa room attendant kinerja nya menurun dari segi kinerja tugas maupun kinerja kontekstual nya. Terakhir peneliti melakukan informal discussion dengan room attendant sebanyak 39 orang selaku objek penelitian. Peneliti mencoba untuk menggali apa sebenarnya yang membuat room attendant tidak bersungguh-sungguh dalam menjalankan pekerjaannya, dan melalui informal discussion didapatkan informasi bahwa room attendant kurang bangga terhadap pekerjaan yang dilakukan dikarenakan room attendant belum memahami tujuan dan makna bekerjanya. Berdasarkan hasil informal discussion tersebut dapat peneliti simpulkan bahwa room attendant belum memiliki kebermaknaan kerja sehingga mempengaruhi kinerja room attendant. Untuk menyimpulkan akar permasalahan yang ditemui, maka peneliti menggunakan analisa 5-Whys seperti Gambar 2. Alasan peneliti menggunakan analisa 5-Whys dalam mendiagnosa akar permasalahan adalah karena dengan analisa 5-Whys maka sebuah problem dapat diidentifikasi hingga pada inti/ akar penyebabnya. Sehingga intervensi yang diberikan mampu mengatasi akar penyebab permasalahan tersebut (tidak hanya mengatasi permukaan permasalahan saja).

Gambar 2 menunjukkan hasil dari analisa 5-Whys dimana setelah digali dengan 5 kali pertanyaan why akhirnya ditemukan bahwa hal yang mendasari kinerja room attendant menurun adalah room attendant masih belum memahami makna dari pekerjaannya. Menanggapi akar permasalahan yang telah peneliti temukan di atas, peneliti melihat bahwa teori kebermaknaan kerja dapat menjadi model yang cocok untuk mengembangkan kinerja room attendant.

\section{Penilaian Kinerja}

Selain melakukan analisa secara kualitatif dengan melakukan observasi, wawancara mendalam, dan informal discussion, peneliti juga menggunakan performance management result untuk mengukur tingkat kinerja karyawan sebelum dilakukannya intervensi. Performance management result yang digunakan oleh Management Bumi Surabaya City Resort untuk menilai kinerja room attendant menggunakan variabel kinerja yang dikemukakan 
oleh Gomes (2003) yang memuat 8 dimensi kinerja diantaranya Quantity of Work, Quality of Work, Job Knowledge, Creativeness, Cooperative, Dependability, Initiative, dan Personal Qualities. Skala likert yang dipakai yaitu 1 sampai dengan 5 (1= Sangat Buruk, 2= Buruk, 3= Sedang, 4= baik, 5= Sangat Baik). Hasil dari performance management result yang diisi oleh team leader dan self assessment untuk menilai kinerja room attendant sebelum dilakukan intervensi nantinya akan dibandingkan dengan hasil post ODI setelah intervensi dilakukan.

\section{Hasil Pengukuran Pre ODI}

Uji Validitas dan Realibilitas

Uji validitas dan realibilitas digunakan untuk mengukur kemampuan dan keandalan sebuah instrumen pengambilan data apakah mampu untuk mempresentasikan kondisi yang ada di lapangan. Suatu item pertanyaan dikatakan valid jika memiliki nilai rhitung (corrected item total correlation) lebih besar dari 0,30. Uji realibilitas dilakukan dengan melihat nilai alpha cronbach, dimana suatu item pertanyaan dinyatakan reliabel jika nilai alpha cronbach lebih besar dari 0,60 (Iskandar, 2008). Pada penelitian ini, peneliti melakukan uji validitas dan realibilitas kepada 39 orang responden dengan menggunakan software SPSS. Hasil uji validitas dan realibilitas dari variabel kinerja karyawan pada Tabel 1.

\section{Analisis Deskriptif Room Attendants' Performance saat} Pre ODI

Berdasarkan Tabel 2 diketahui bahwa nilai rata-rata performance adalah sebesar 2,84. Dari hasil ini juga dapat dilihat bahwa indikator performance terendah terletak pada dimensi initiative dengan rata-rata nilainya sebesar 2,75. Setelah itu terdapat dimensi dependability dan quality of work dengan total mean yang sama yaitu sebesar 2,79 yang mana semakin memperkuat hasil diagnosa yang peneliti lakukan yaitu room attendant kurang maksimal dalam menyelesaikan tugas nya yang terlihat dari room attendant cenderung bekerja kurang teliti dan detail serta bekerja kurang sesuai dengan SOP. Oleh karena itu, berdampak pada dimensi dependability dimana room attendant kurang dapat dipercaya dalam hal penyelesaian kerja. Sedangkan untuk dimensi lainnya seperti personal quality, cooperation, creativeness, job knowledge, dan quantity of work juga masih memiliki total mean yang rendah.
Why l: Mengapa kinerja room attendant menurun?

Answer : Karena room attendant tidak termotivasi dalam bekerja.

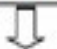

Why 2: Mengapa room attendant tidak termotivasi dalam bekerja?

Ansver: Karena room attendont kurang bangea terhadap pekerjan yang dilakukan.

Why 3: Mengapa room attendant kurang bangega terhadap pekerjan yang dilakukan? Answer: Karena room attendant merasa pekerjaranya dipandang rendah' tidak penting.

Why 4: Mengapa room attendant merasa pekerjaannya dipandang rendab/ tidak penting? Alswer : Karena room attendant belum memalami pentingnya peran pekerjannya dalam industri perhotelan.

\.

Why 5: Mengapa room attendont behum memahami pentingnya peran pekerjaannya dalam industri perhotelan?

Answer : Karena room attendont belum memahami makna dari pekerjaannya bag̣ diri sendiri, orang lain, dan indsstri perhotelan itu sendiri.

Gambar 2. Analisis 5-Whys

Tabel 1. Uji validitas dan realibilitas variabel kinerja karyawan

\begin{tabular}{cccc}
\hline Indikator & $\begin{array}{c}\text { Corrected } \\
\text { Item Total } \\
\text { Corelation }\end{array}$ & $\begin{array}{c}\text { Cronbach's } \\
\text { Alpha }\end{array}$ & Keterangan \\
\hline QTY1 & 0,522 & & Valid dan Reliabel \\
QTY2 & 0,584 & & Valid dan Reliabel \\
QLY1 & 0,563 & & Valid dan Reliabel \\
QLY2 & 0,741 & & Valid dan Reliabel \\
KWG1 & 0,564 & & Valid dan Reliabel \\
KWG2 & 0,590 & & Valid dan Reliabel \\
CTV1 & 0,536 & & Valid dan Reliabel \\
CTV2 & 0,428 & 0,908 & Valid dan Reliabel \\
CPT1 & 0,628 & & Valid dan Reliabel \\
CPT2 & 0,673 & & Valid dan Reliabel \\
DPY1 & 0,520 & & Valid dan Reliabel \\
DPY2 & 0,482 & & Valid dan Reliabel \\
INT1 & 0,634 & & Valid dan Reliabel \\
INT2 & 0,636 & & Valid dan Reliabel \\
PQT1 & 0,618 & & Valid dan Reliabel \\
PQT2 & 0,712 & & Valid dan Reliabel \\
\hline
\end{tabular}


Tabel 2. Deskriptif jawaban team leader terkait kinerja room attendant saat Pre ODI

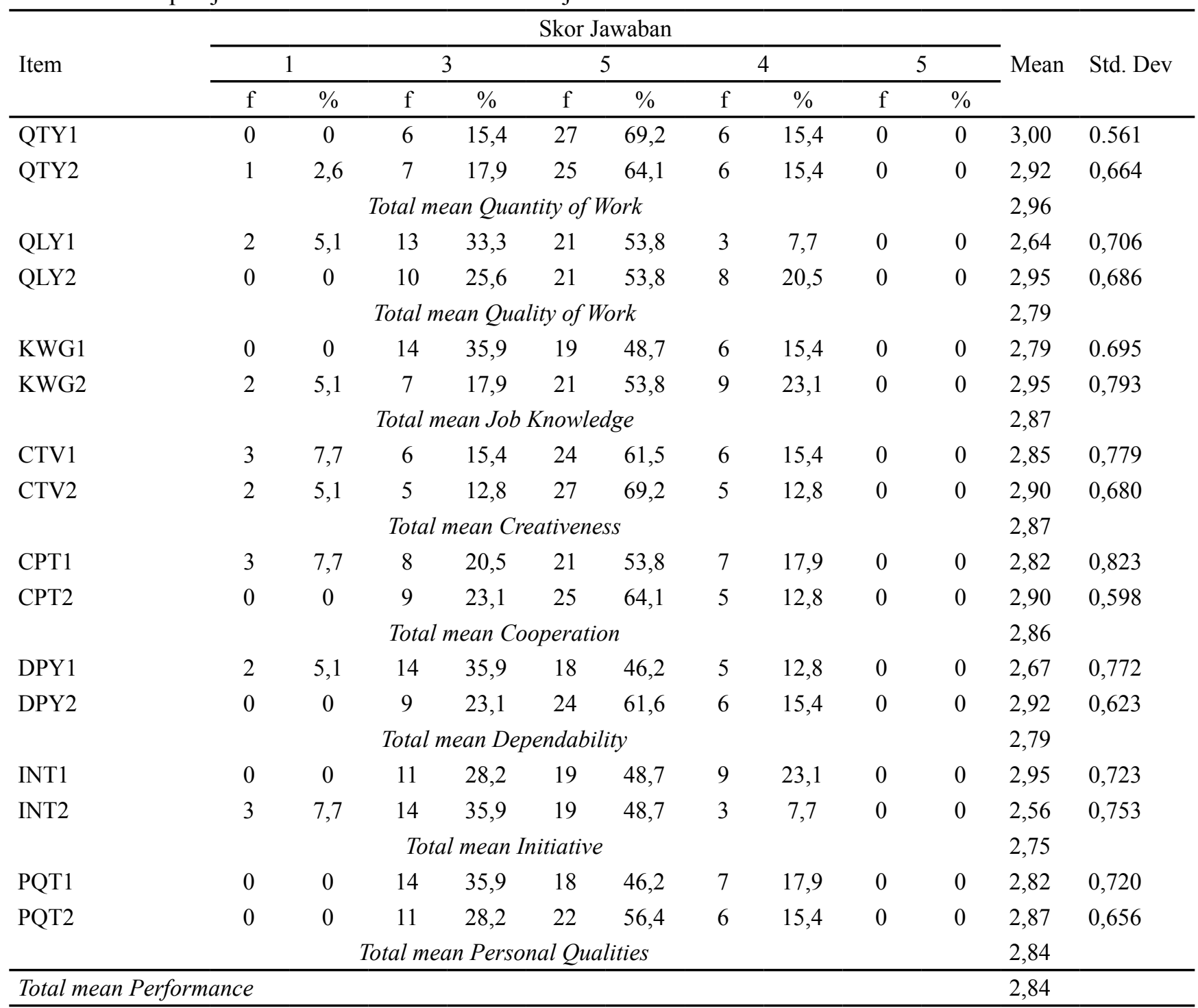

Berdasarkan Tabel 3 diketahui bahwa nilai ratarata performance adalah sebesar 3,03. Dari hasil ini juga dapat dilihat bahwa indikator performance terendah terletak pada dimensi dependability dengan mean sebesar 2,86; initiative dengan mean sebesar 2,94 dan quality of work dengan mean sebesar 2,96 yang mana semakin memperkuat hasil diagnosa peneliti yaitu room attendant kurang berinisiatif untuk memperbaiki hal-hal yang ditemui tidak sesuai standar dan kurangnya bekerja sesuai SOP. Setelah itu terdapat dimensi creativeness dengan mean sebesar 3,04; dimensi cooperation dengan mean sebesar 3,06; dimensi job knowledge dengan mean sebesar 3,08; dimensi personal qualities dengan mean sebesar 3,14; dan dimensi quantity of work dengan mean sebesar 3,17. Secara keseluruhan kedelapan dimensi tersebut memiliki total mean yang rendah.

\section{ODI}

Pada tahap ini peneliti melakukan intervensi berupa training kepada team leader dan room attendant. Setelah itu team leader yang akan memberikan coaching secara personal kepada room attendant serta nantinya peneliti akan melakukan follow up session kepada team leader guna memastikan apakah coaching berjalan dengan lancar serta memastikan kinerja yang diharapkan perusahaan terkait delapan dimensi kinerja sudah diterapkan oleh room attendant. Aktivitas kegiatan ODI yang dilakukan ditunjukkan pada Tabel 4. Selanjutnya, Matrix Training \& Coaching Kebermaknaan Kerja pada Tabel 5. 
Tabel 3. Deskriptif Jawaban Room Attendant sendiri terkait kinerja nya saat Pre ODI

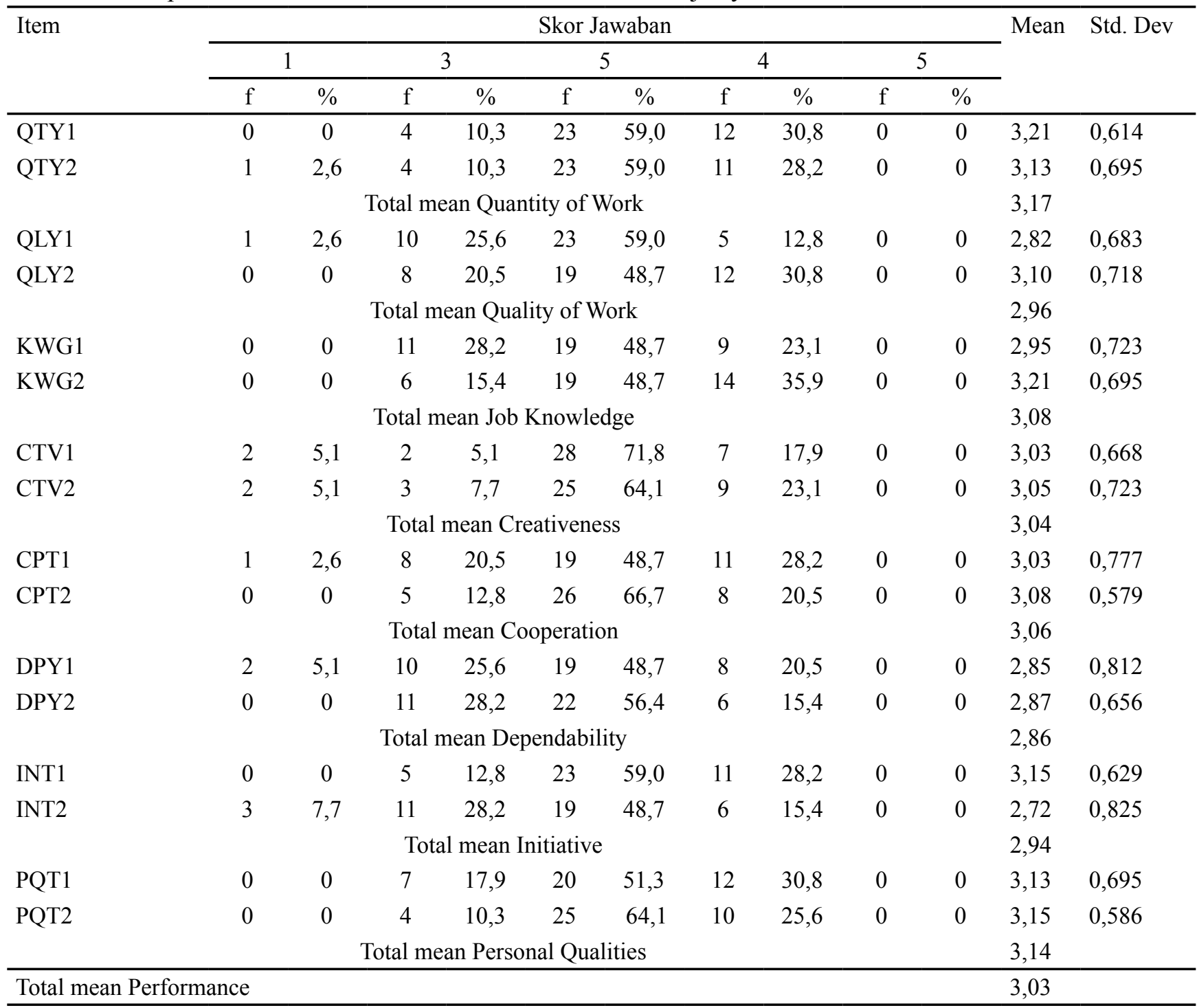

Tabel 4. Proses Kegiatan ODI "Kebermaknaan Kerja"

\begin{tabular}{|c|c|}
\hline \multicolumn{2}{|r|}{ Sesi Pertama } \\
\hline ODI & Training Session dengan tema kebermaknaan kerja terkait dengan kinerja karyawan \\
\hline Target & Room Attendant \\
\hline Tujuan & $\begin{array}{l}\text { Meningkatkan rasa kebermaknaan kerja pada pemikiran dan perasaan Room attendant yang pada akhirnya dapat } \\
\text { menunjang performance Room attendant. }\end{array}$ \\
\hline $\begin{array}{l}\text { Aktivitas } \\
\text { Training }\end{array}$ & $\begin{array}{l}\text { Penjelasan terkait dengan hasil Pre ODI yang telah ditemukan baik melalui observasi, indepth interview, informal } \\
\text { discussion, dan penilaian kinerja. Setelah itu peneliti menjelaskan dan mengarahkan sudut pandang Room attendant } \\
\text { dengan menjelaskan tiga dimensi dari kebermaknaan kerja yang dapat menunjang performance Room attendant. }\end{array}$ \\
\hline Hasil & $\begin{array}{l}\text { - Room attendant mengetahui bahwa performance mereka mengalami penurunan dari segi kedelapan dimensi kinerja. } \\
\text { - Room attendant memahami pentingnya memiliki kebermaknaan kerja melalui tiga dimensi kebermaknaan kerja. } \\
\text { - Room attendant dapat menyadari bahwa sebenarnya pekerjaan yang Room attendant lakukan sangat bermakna dan } \\
\text { pada akirnya Room attendant dapat bekerja dengan lebih bersungguh-sungguh dan memaksimalkan potensi yang } \\
\text { dimiliki. }\end{array}$ \\
\hline \multicolumn{2}{|r|}{ Sesi Kedua } \\
\hline ODI & Training Session dengan tema Kebermaknaan Kerja dan Panduan Coaching \\
\hline Target & Team leader \\
\hline Tujuan & $\begin{array}{l}\text { Team leader dapat mengetahui perlunya menanamkan rasa kebermaknaan kerja pada Room attendant dan dapat } \\
\text { memahami bagaimana memberikan coaching yang tepat bagi Room attendant guna meningkatkan performance Room } \\
\text { attendant. }\end{array}$ \\
\hline Aktivitas & $\begin{array}{l}\text { Penjelasan terkait dengan hasil Pre ODI yang telah ditemukan. Setelah itu peneliti juga menjelaskan tiga dimensi } \\
\text { kebermaknaan kerja dan panduan performance coaching yang akan digunakan Team leader dalam mengcoaching } \\
\text { Room attendant dalam rangka meningkatkan kinerja Room attendant. }\end{array}$ \\
\hline
\end{tabular}


Tabel 4. Proses Kegiatan ODI “Kebermaknaan Kerja” (lanjutan)

\begin{tabular}{|c|c|}
\hline $\begin{array}{l}\text { Hasil dari } \\
\text { Training }\end{array}$ & $\begin{array}{l}\text { Team leader memahami teknik performance coaching yang tepat untuk Room attendant dimana pada coaching } \\
\text { tersebut Team leader juga harus terus menanamkan rasa kebermaknaan kerja didalam diri tiap Room attendant. }\end{array}$ \\
\hline \multicolumn{2}{|r|}{ Sesi Ketiga } \\
\hline ODI & Coaching Session antara Team leader dan Room attendant \\
\hline Target & Room attendant \\
\hline Tujuan & $\begin{array}{l}\text { Room attendant secara personal mendapatkan coaching dari Team leader sehingga Team leader dapat lebih memahami } \\
\text { dan membantu kesulitan yang dihadapi oleh tiap Room attendant serta dapat menumbuhkan rasa kebermaknaan kerja } \\
\text { bagi person tersebut yang pada akhirnya akan menunjang Room attendant performance. }\end{array}$ \\
\hline Aktivitas & $\begin{array}{l}\text {-Team leader mendengarkan dan memahami keadaan serta kebutuhan coachee } \\
\text {-Team leader memaparkan tingkat kinerja dari Room attendant tersebut berdasarkan performance management result } \\
\text {-Team leader memaparkan kinerja yang diharapkan perusahaan } \\
\text { - Room attendant menuliskan komitmennya pada lembar Coaching. }\end{array}$ \\
\hline Hasil & Team leader bersama Room attendant menetukan action plan sebagai langkah perubahan yang disesuaikan dengan \\
\hline
\end{tabular}
indikator performance.

\begin{tabular}{ll}
\hline & \\
\hline ODI & Follow up Session atau proses lanjutan dari tahap coaching yang peneliti lakukan dengan Team leader. \\
Target & Team Leader \\
Tujuan & Memastikan kinerja yang diharapkan perusahaan terkait delapan dimensi kinerja sudah diterapkan oleh Room \\
& attendant.
\end{tabular}

Aktivitas Peneliti menanyakan terkait dengan implementasi dari tiap indikator kinerja yang telah dilakukan Room attendant serta meninjau kembali action plan yang belum dilakukan oleh Room attendant. Peneliti juga turut memberikan saran terkait dengan kendala yang dihadapi saat implementasi indikator kinerja.

Hasil dari Ditahap ini peneliti melakukan sesi follow up untuk melihat hasil implementasi dari action plan yang telah disepakati follow up bersama. Berikut adalah hasil follow up yang peneliti lakukan:

Session 1. Quantity of Work: Dari segi kuantitas bekerja, Room attendant sudah dapat mencapai target yang diharapkan perusahaan yaitu per harinya 14 kamar yang disiapkan untuk dijual.

2. Quality of Work: Room attendant sudah lebih concern terhadap SOP serta dapat mengerjakan tugas dengan lebih teliti dan detail.

3. Job Knowledge: Room attendant sudah lebih concern terhadap pertumbuhan pribadinya yang terlihat dari kemauan Room attendant untuk mengikuti Training yang diadakan hotel untuk meng-upgrade pengetahuan dan skill.

4. Creativeness: Room attendant lebih berani menyampaikan gagasan/ idenya dan dapat bertindak kreatif saat dibutuhkan.

5. Cooperative: Room attendant sudah mau menjalin kerjasama bukan hanya dengan rekan kerja dan atasan nya dalam satu divisi, melainkan juga dengan divisi yang lain.

6. Dependability: Room attendant sudah dapat dipercaya dalam hal penyelesaian tugas dan kehadiran.

7. Initiative: Ketika terdapat hal-hal dikamar tamu yang tidak sesuai dengan standar dan perlu bantuan dari departemen lain, Room attendant sudah bisa berinisiatif untuk menjalin kerjasama dengan departemen lain guna memperbaiki hal tersebut.

8. Personal Qualities: GRooming Room attendant sudah lebih baik dari sebelumnya dan juga Room attendant sudah lebih ramah terhadap orang yang dijumpai.

Saran Peneliti juga membantu memberikan solusi terkait dengan permasalahan yang dihadapi oleh Team leader. Permasalahan yang dihadapi adalah terkadang Room attendant lupa untuk melakukan final Room checking setelah mengerjakan kamar sehingga masih terdapat hal-hal yang terlupakan. Untuk itu peneliti memberikan saran agar Team leader dapat memberikan panduan yang jelas bagi Room attendant berupa penambahan aktivitas final Room checking dengan metode pengecekan searah jarum jam pada list SOP bekerja Room attendant sehingga Room attendant dapat selalu ingat bahwa setelah mengerjakan kamar wajib melakukan final Room checking. Untuk itu peneliti kembali memberikan hasil diagnosa yang telah dilakukan saat Pre ODI agar Team leader mau memastikan action plan tersebut dilakukan secara benar oleh Room attendant dikarenakan aktivitas final Room checking juga sangat berpengaruh pada dimensi quality of work. Setelah itu peneliti dan Team leader kembali membuat kesepakatan untuk menjalankan sisa action plan yang belum dilakukan. 


\begin{tabular}{ll}
\hline Intervensi & Aktivitas/ Metode \\
Kebermaknaan Kerja & \\
\hline Dimensi 1: Positive & Training: Peneliti mengajarkan room attendant mengenai tiga indikator yang terkait dengan dimensi positive \\
Meaning in Work & meaning in work diantaranya: \\
& 1. Penjelasan terkait jenjang karir yang akan ditempuh room attendant. \\
& 2. Penjelasan terkait makna dibalik pekerjaan yang room attendant lakukan. \\
& 3. Penjelasan terkait pentingnya memiliki pemikiran dan perasaan yang positif tentang pekerjaan yang \\
& dilakukan. \\
& Coaching: Dilakukan secara personal antara team leader dengan room attendant guna menanyakan pemahaman \\
& room attendant terhadap tiga indikator dalam dimensi positive meaning in work serta kasus yang dialami per \\
& individu. Terakhir dibuat action plan guna memperbaiki kinerja room attendant.
\end{tabular}

Dimensi 2: Meaning Making Through Work

Dimensi 3: Greater Good Motivation
Training: Peneliti mengajarkan room attendant mengenai tiga indikator yang terkait dengan dimensi meaning making through work diantaranya:

1. Penjelasan mengenai berbagai kegiatan pengembangan diri yang dapat diikuti oleh room attendant.

2. Bagaimana sikap dan karakter yang perlu dimiliki room attendant untuk menunjang karirnya.

3. Perlunya room attendant memiliki kepekaan terhadap lingkungan sekitar.

Coaching: Dilakukan secara personal antara team leader dengan room attendant guna menanyakan pemahaman room attendant terhadap tiga indikator dalam dimensi meaning making through work serta kasus yang dialami per individu. Terakhir dibuat action plan guna memperbaiki kinerja room attendant.

Training: Peneliti mengajarkan room attendant mengenai tiga indikator yang terkait dengan dimensi greater good motivation diantaranya:

1. Penjelasan bahwa pekerjaan yang dilakukan room attendant memiliki dampak atau pengaruh positif terhadap orang lain.

2. Room attendant disadarkan bahwa hasil pekerjaannya membuat kemajuan positif bagi perusahaan.

3. Room attendant disadarkan bahwa pekerjaan yang dilakukannya memiliki tujuan yang mulia.

Coaching: Dilakukan secara personal antara team leader dengan room attendant guna menanyakan pemahaman room attendant terhadap tiga indikator dalam dimensi greater good motivation serta kasus yang dialami per individu. Terakhir dibuat action plan guna memperbaiki kinerja room attendant.

\section{Post ODI}

Pada tahap ini peneliti melakukan evaluasi terhadap hasil intervensi kebermaknaan kerja dengan metode training dan coaching yang telah peneliti lakukan. Dalam evaluasi ini peneliti mengukur perubahan dari kinerja karyawan setelah dilakukannya intervensi. Performance management result kembali diisi oleh team leader setelah dilakukannya intervensi kepada room attendant lalu room attendant juga diminta untuk menilai kinerja nya sendiri. Berdasarkan observasi yang peneliti lakukan pada tahap Post ODI ini ditemukan bahwa room attendant sudah mulai menerapkan kedelapan dimensi performance dalam menjalankan perannya dalam bekerja. Room attendant juga sudah menunjukkan ketelitian dan kesungguhannya dalam bekerja. Lalu melalui informal discussion, room attendant juga menuturkan bahwa mereka sudah lebih paham akan tujuan dan makna pekerjaan mereka. Selain itu melalui interview, Talent \& Learning Manager juga turut mengapresiasi kinerja room attendant yang sudah mulai membaik. Room attendant menjadi lebih termotivasi karena mereka sudah lebih jelas mengetahui tujuan-tujuan yang akan dicapai dalam pekerjaan mereka secara lebih mendetail. Hal ini memungkinkan room attendant untuk selalu termotivasi bekerja sesuai dengan ketentuan dan target perusahaan.

Berdasarkan Tabel 6 dapat dilihat bahwa total mean untuk performance adalah sebesar 3,96. Nilai mean yang paling tinggi terdapat pada dimensi job knowledge dengan nilai 4,01. Selanjutnya terdapat mean quantity of work sebesar 4,00. Diurutan ketiga terdapat mean cooperation sebesar 3,98. Kemudian terdapat dimensi creativeness, dependability, initiative, quality of work, dan personal qualities. Dari hasil keseluruhan indikator di atas dapat dilihat bahwa terdapat perubahan ke arah yang lebih baik dibandingkan dengan hasil Pre ODI. Ini artinya bahwa room attendant sudah mengalami peningkatan terkait dengan performance, karena telah diberikannya intervensi kebermaknaan kerja kepada room attendant. 
Tabel 6. Deskriptif Jawaban Team Leader pada Kinerja Room Attendant saat Post ODI

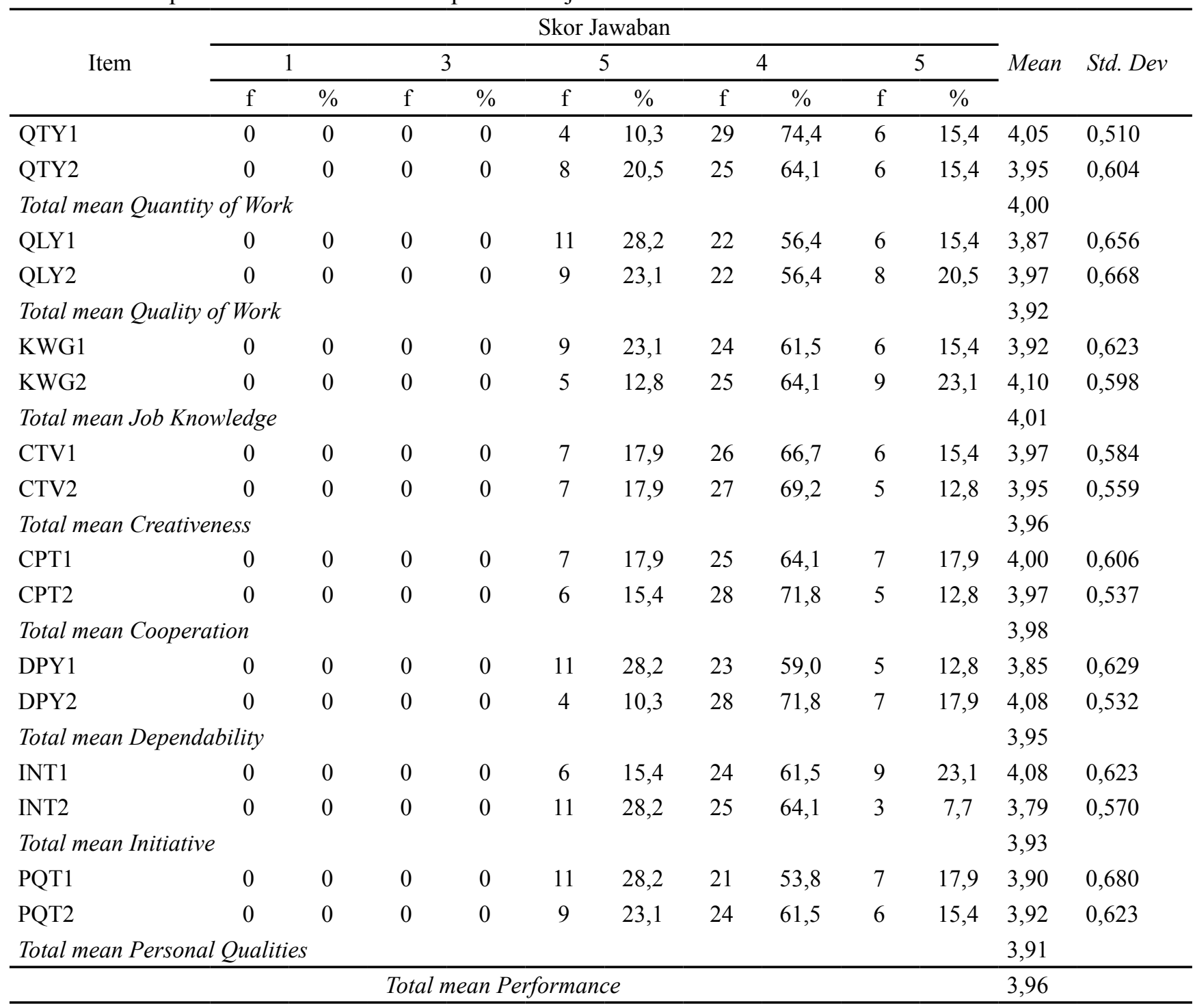

Berdasarkan Tabel 7 dapat dilihat bahwa total mean untuk performance adalah sebesar 3,43. Nilai mean dimensi yang paling tinggi terdapat pada quantity of work dengan nilai 3,50. Selanjutnya terdapat dimensi initiative sebesar 3,48; dimensi cooperation dan personal qualities dengan nilai mean sebesar 3,45; dimensi quality of work dengan nilai mean sebesar 3,42; dimensi job knowledge dan dependability 3,40 serta yang terakhir dimensi creativeness dengan nilai mean sebesar 3,35. Dari hasil keseluruhan indikator di atas dapat dilihat bahwa terdapat perubahan ke arah yang lebih baik dibandingkan hasil Pre ODI. Ini artinya bahwa room attendant juga menilai bahwa tingkat kinerja nya sudah mengalami peningkatan, karena telah diberikannya intervensi kebermaknaan kerja kepada room attendant.

\section{Hasil perbandingan Pre ODI dengan Post ODI Kinerja Karyawan}

Berdasarkan Tabel 8 dapat dilihat bahwa rata-rata penilaian kinerja saat Post ODI $(3,96)$ lebih besar dari rata-rata jawaban saat Pre ODI $(2,84)$. Nilai $t$ dari hasil pengujian tersebut sebesar -52,918 dengan nilai signifikan sebesar 0,000 yang berarti terdapat perbedaan yang signifikan antara skor rata-rata Pre ODI dengan rata-rata skor Post ODI. Hasil ini menunjukkan bahwa room attendant memiliki peningkatan pada performance. Berdasarkan Tabel 9 dapat dilihat bahwa rata-rata penilaian kinerja saat Post ODI $(3,43)$ lebih besar dari rata-rata jawaban saat Pre ODI $(3,03)$. Nilai t dari hasil pengujian tersebut sebesar $-9,238$ dengan nilai signifikan sebesar 0,000 yang berarti terdapat perbedaan yang signifikan antara rata-rata skor Pre ODI dengan rata-rata skor Post ODI. Hasil ini menunjukkan bahwa room attendant memiliki peningkatan pada performance. 
Tabel 7. Deskriptif Jawaban Room Attendant terkait Kinerjanya saat Post ODI

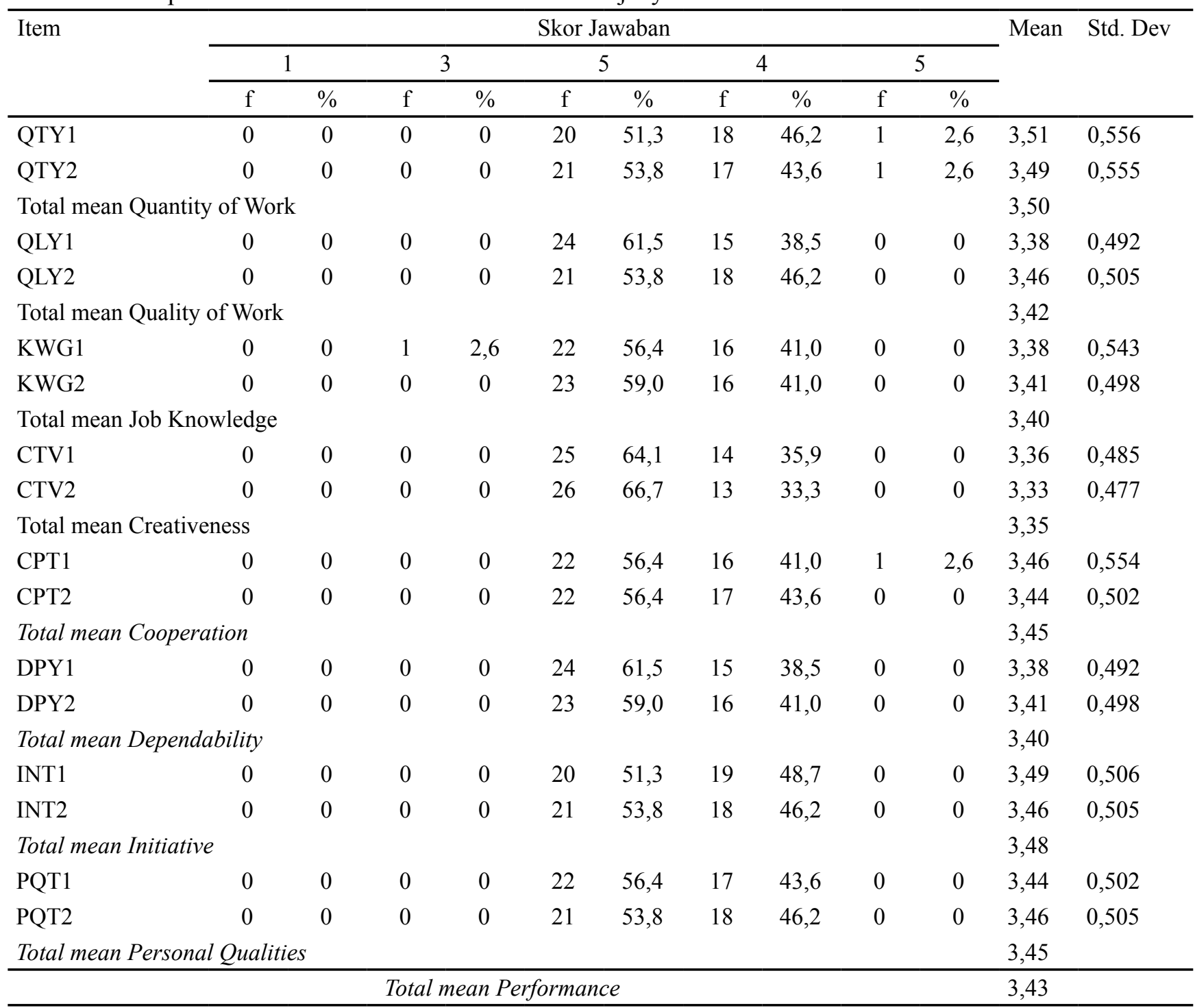

Tabel 8. Perbandingan Pre ODI dan Post ODI Jawaban Team Leader terkait Kinerja Room Attendant

\begin{tabular}{llllll}
\hline Data & Mean & Standar Deviasi & T & Df & Sig (2-tailed) \\
\hline Pre ODI & 2,84 & 0,456 & $-52,918$ & 38 & 0,000 \\
Post ODI & 3,96 & 0,367 & & & \\
\hline
\end{tabular}

Tabel 9. Perbandingan Pre ODI dan Post ODI Jawaban Room Attendant terkait Kinerjanya

\begin{tabular}{llllll}
\hline Data & Mean & Standar Deviasi & T & Df & Sig (2-tailed $)$ \\
\hline Pre ODI & 3,03 & 0,387 & $-9,238$ & 38 & 0,000 \\
Post ODI & 3,43 & 0,185 & & & \\
\hline
\end{tabular}

Terkait dengan pengukuran dari dua sisi yaitu dari team leader dan room attendant sendiri, maka peneliti mengakui bahwa hal tersebut dikarenakan team leader ikut serta dalam intervensi ini sehingga untuk mengeliminasi bias penilaian maka room attendant juga diminta untuk menilai kinerjanya sendiri. Hasil penilaian dari dua sisi ini menunjukkan adanya perbedaan nilai mean Pre dan Post ODI yang samasama signifikan. Namun, dibandingkan selisih mean
Pre dan Post ODI nya maka penilaian dari team leader memiliki selisih mean yang lebih besar dari penilaian room attendant.

\section{Implikasi Manajerial}

Penelitian ini dilakukan untuk mengatasi permasalahan yang terjadi di Bumi Surabaya City Resort terkait dengan penurunan kinerja room attendant beberapa 
bulan terakhir ini. Dengan adanya Organization Development Intervention (ODI) yang merupakan program terstruktur yang dirancang untuk memecahkan masalah organisasi maka peneliti dan management melihat hasil penerapan intervensi berupa training dan coaching kebermaknaan kerja memiliki implikasi yang singnifikan pada peningkatan kinerja room attendant. Pimpinan organisasi perlu memfasilitasi bawahan saat bekerja bukan hanya sekedar mengajari tentang skill namun juga mampu memberdayakan karyawan secara psikologis, sehingga karyawan dapat memiliki motivasi yang tepat saat melaksanakan pekerjaannya. Organisasi perlu meningkatkan rasa kebermaknaan kerja pada karyawannya, agar tiap karyawan dapat termotivasi untuk memberikan kinerja yang terbaik. Ketika karyawan termotivasi untuk bekerja dengan baik, maka produktivitas organisasi juga akan meningkat. Kebermaknaan kerja juga dirasa tepat untuk digunakan dalam lingkungan bisnis yang dinamis dan kompetitif saat ini. Selain itu, Wrzesniewski dan Dutton (2001) mengatakan karakteristik pekerjaan bukan sekedar objective yang diberikan, tetapi para pemegang jabatan perlu aktif berpartisipasi dalam membentuk karakteristik pekerjaan dan mengembangkan persepsi tentang karakteristik ini.

\section{KESIMPULAN DAN SARAN}

\section{Kesimpulan}

Pada tahap Pre ODI peneliti melakukan wawancara mendalam terhadap Talent \& Learning Manager dan Housekeeping Manager. Peneliti menemukan adanya masalah terkait dengan kinerja room attendant yang rendah. Untuk semakin memperkuat hasil diagnosa, peneliti menggunakan performance management result guna menilai tingkat kinerja room attendant yang mana hasil penilaian didapatkan total mean performance room attendant saat Pre ODI sebesar 2,84 (Penilaian dari team leader) sedangkan self assessment didapatkan score kinerja room attendant sebesar 3,03. Lalu dari hasil informal discussion bersama room attendant, peneliti mendapatkan informasi bahwa kinerja room attendant yang menurun tersebut dikarenakan room attendant belum memahami tujuan dan makna bekerjanya. Pada tahap ODI peneliti memberikan training dan coaching "Kebermaknaan Kerja" terkait tiga dimensi kebermaknaan kerja untuk meningkatkan item-item kinerja. Dari hasil training dan coaching yang diberikan kepada room attendant, peneliti dan team leader melakukan kesepakatan dengan room attendant untuk lebih concern terhadap peningkatan kinerja room attendant. Setelah diberikannya coaching, peneliti kembali melakukan follow up session kepada team leader untuk melihat hal apa saja yang masih menjadi kendala dalam proses ODI. Peneliti juga berusaha meyakinkan agar itemitem kinerja dapat terus diterapkan secara konsisten oleh room attendant. Pada tahapan Post ODI, peneliti kembali memberikan performance management result yang sama dengan saat Pre ODI kepada team leader guna menilai performance room attendant setelah dilakukannya intervensi. Hasil dari performance management result yang dibagikan pada saat Pre ODI dan Post ODI kemudian dibandingkan dan dilihat apakah terdapat perbedaan setelah dilakukannya intervensi. Dari hasil Post ODI terlihat bahwa terdapat kenaikan nilai rata-rata (mean) dari tiap indikator yang diuji dan total mean performance yang diperoleh pada saat post ODI yaitu sebesar 3,96 (penilaian dari team leader) sedangkan dari self assessment diperoleh score post ODI sebesar 3,43. Selain itu, berdasarkan hasil indepth interview dengan beberapa room attendant dan Manajer diketahui bahwa terdapat implikasi positif dari intervensi kebermaknaan kerja yang diterapkan oleh peneliti. Hasil penelitian menunjukkan intervensi training dan coaching kebermaknaan kerja mampu meningkatkan score kinerja karyawan 2,84 menjadi 3,96 (menurut penilaian team leader) serta 3,03 menjadi 3,43 (menurut room attendant sendiri). Dengan demikian, hipotesis penelitian dapat diterima yaitu terdapat perbedaan rata-rata skor kinerja karyawan sebelum dan setelah dilakukannya intervensi.

\section{Saran}

Housekeeping Manager dan Team Leader perlu terus melakukan monitoring terkait dengan perilaku dan hasil kerja room attendant agar menjadi suatu perilaku yang konsisten dilakukan seterusnya. Team leader perlu melakukan kegiatan coaching secara berkelanjutan serta perlu melakukan evaluasi dengan meminta feedback dari room attendant. Motivasi berupa kebermaknaan kerja dan apresiasi perlu terus diberikan agar room attendant dapat terus bersemangat dalam mempertahankan kinerjanya. Intervensi seperti ini dapat diterapkan pada divisi lain jika ditemukan penyebab masalah menurunnya kinerja karyawan divisi tersebut adalah kurangnya kebermaknaan kerja. Untuk penelitian selanjutnya, bisa menerapkan intervensi 
kebermaknaan kerja pada objek yang berbeda dengan tetap mengindentifikasi terlebih dahulu akar penyebab permasalahan.

\section{DAFTAR PUSTAKA}

Almutoif B. 2019. Bisnis hotel tahun 2019 kian berat. https://jatimnet.com/bisnis-hotel-tahun-2019kian-berat. [1 Desember 2019].

Aguinis H, Kraiger K. 2009. Benefit of training and development for individuals and teams, organizations, and society. Annual Review of Psychology 60: 451-474.

Cummings TG, Worley CG. 2009. Organizational development and change. USA: South-Western College Publishing.

Evans, Campbell, Stonehouse. 2003. Strategic Management for Travel and Tourism. Oxford: Butterworth-Heinemann.

Gomes, FC. 2003. Manajemen Sumber Daya Manusia. Yogyakarta: Andi Offset.

Iskandar. 2008. Metodologi penelitian pendidikan dan sosial (kuantitatif dan kualitatif). Jakarta: Gaung Persada.

Julianry A, Syarief R, Affandi MJ. 2017. Pengaruh pelatihan dan motivasi terhadap kinerja karyawan serta kinerja organisasi kementrian komunikasi dan informatika. Jurnal Aplikasi Bisnis dan Manajemen 3(2): 236-245.
Rachman E, Jakob E. 2018. Meaningful work. https:// www.experd.com/en/articles/2018/04/725/ meaningful-work.html. [2 Desember 2019].

Siregar S. 2015. Statistika Terapan Untuk Perguruan Tinggi. Jakarta: Prenadamedia Group.

Spreitzer, GM. 1995. Psychological empowerment in the workplace: dimensions, measurement, and validation. Academy of Management Journal 38: 1442-1465.

Steger MF, Dik BJ, Duffy RD. 2012. Measuring meaningful work: the work and meaning inventory (WAMI). Journal of Career Assesment 20(3): 322-337.

Tong L. 2018. Relationship between meaningful work and job performance in nurses. International Journal of Nursing Practice 24(2).

Ulrich D, Ulrich W .2010. The why of work: How great leaders build abundant organizations that win. New York: McGraw-Hill.

Wrzesniewski A \& Dutton JE .2001. Crafting a job: Revisioning employees as active crafters of their work. Academy of Management Review 26: 179201.

Wrzesniewski A, Dutton JE, Debebe G. 2003. Interpersonal sensemaking and the meaning of work. Research in Organizational Behavior 25: 93-135.

Zeglat D, Janbeik S .2019. Meaningful work and organizational outcomes: The mediating role of individual work performance. Management Research Review 42(7): 859-878. 